TAMKANG JOURNAL OF MATHEMATICS

Volume 33, Number 2, Summer 2002

\title{
ON THE PERTURBED TRAPEZOID FORMULA
}

\author{
N. S. BARNETT AND S. S. DRAGOMIR
}

\begin{abstract}
Some inequalities related to the perturbed trapezoid formula are given. An application for the expectation of a random variable is also pointed out.
\end{abstract}

\section{Introduction}

In [3], the authors have pointed out the following trapezoid inequality in terms of the $p$-norms of the second derivative.

Theorem 1. Let $f:[a, b] \rightarrow \mathbb{R}$ be a twice differentiable function on $(a, b)$. Then we have the estimate

$$
\begin{aligned}
&\left|\int_{a}^{b} f(x) d x-\frac{b-a}{2}[f(a)+f(b)]\right| \\
& \leq\left\{\begin{array}{lc}
\frac{\left\|f^{\prime \prime}\right\|_{\infty}}{12}(b-a)^{3} & \text { if } f^{\prime \prime} \in L_{\infty}[a, b] ; \\
\frac{1}{2}\left\|f^{\prime \prime}\right\|_{p}[B(q+1, q+1)]^{\frac{1}{q}}(b-a)^{2+\frac{1}{q}}, & \text { if } f^{\prime \prime} \in L_{p}[a, b], \\
& p>1, \frac{1}{p}+\frac{1}{q}=1 ; \\
\frac{\left\|f^{\prime \prime}\right\|_{1}}{8}(b-a)^{2} & \text { if } f^{\prime \prime} \in L_{1}[a, b] ;
\end{array}\right.
\end{aligned}
$$

where

$$
\begin{aligned}
\left\|f^{\prime \prime}\right\|_{\infty} & :=\sup _{t \in[a, b]}\left|f^{\prime \prime}(t)\right|, \\
\left\|f^{\prime \prime}\right\|_{1} & :=\int_{a}^{b}\left|f^{\prime \prime}(t)\right| d t
\end{aligned}
$$

and

$$
\left\|f^{\prime \prime}\right\|_{p}:=\left(\int_{a}^{b}\left|f^{\prime \prime}(t)\right|^{p} d t\right)^{\frac{1}{p}}, \quad p>1
$$

and $B$ is the Beta function, that is,

$$
B(r, s):=\int_{0}^{1} t^{r-1}(1-t)^{s-1} d t, \quad r, s>0 .
$$

Received May 1, 2001; revised June 8, 2001.

2000 Mathematics Subject Classification. Primary 26D15; Secondary 26D10, 26D99, 41A55.

Key words and phrases. Purturbed trapezoid formula. 
Using Grüss' integral inequality, the following perturbed trapezoid inequality in terms of the upper and lower bounds of the second derivative, may be stated (see [3]):

Theorem 2. Let $f:[a, b] \rightarrow \mathbb{R}$ be a twice differentiable function on $(a, b)$ and assume that

$$
\gamma:=\inf _{x \in(a, b)} f^{\prime \prime}(x)>-\infty \text { and } \Gamma:=\sup _{x \in(a, b)} f^{\prime \prime}(x)<\infty .
$$

Then we have the estimation

$$
\begin{aligned}
& \left|\int_{a}^{b} f(x) d x-\frac{b-a}{2}[f(a)+f(b)]+\frac{(b-a)^{2}}{12}\left[f^{\prime}(b)-f^{\prime}(a)\right]\right| \\
\leq & \frac{1}{32}(\Gamma-\gamma)(b-a)^{3} .
\end{aligned}
$$

In [2], by the use of a finer argument based on the pre-Grüss inequality, the authors have improved (1.3) as follows.

Theorem 3. If $f$ is as in Theorem 2, then

$$
\begin{aligned}
& \left|\int_{a}^{b} f(x) d x-\frac{b-a}{2}[f(a)+f(b)]+\frac{(b-a)^{2}}{12}\left[f^{\prime}(b)-f^{\prime}(a)\right]\right| \\
\leq & \frac{1}{24 \sqrt{5}}(b-a)^{3}(\Gamma-\gamma),
\end{aligned}
$$

where $\gamma$ and $\Gamma$ are given in $(1.2)$.

Remark 1. Atkinson [1] defines the quadrature rule

$$
P T(f ; a, b):=\frac{b-a}{2}[f(a)+f(b)]-\frac{(b-a)^{2}}{12}\left[f^{\prime}(b)-f^{\prime}(a)\right]
$$

as a corrected trapezoidal rule and obtains it using an asymptotic error estimate approach which does not provide an expression for the error bound.

In this paper we point out different bounds for the corrected trapezoidal rule. A natural application for the expectation of a random variable is also given.

\section{The Results}

We have the following representation result.

Lemma 1. Let $f:[a, b] \rightarrow \mathbb{R}$ be a differentiable function so that $f^{\prime}$ is absolutely continuous on $[a, b]$. Then we have the representation:

$$
\int_{a}^{b} f(x) d x-\frac{b-a}{2}[f(a)+f(b)]+\frac{(b-a)^{3}}{12}\left[f^{\prime} ; a, b\right]
$$




$$
=\frac{1}{2} \int_{a}^{b}(x-a)(b-x)\left\{\left[f^{\prime} ; a, b\right]-f^{\prime \prime}(x)\right\} d x
$$

where

is the divided difference.

$$
\left[f^{\prime} ; a, b\right]:=\frac{f^{\prime}(b)-f^{\prime}(a)}{b-a}
$$

Proof. By twice applying the integration by parts formula, we may state (see for example [1]) that

$$
\int_{a}^{b} f(x) d x-\frac{b-a}{2}[f(a)+f(b)]=-\frac{1}{2} \int_{a}^{b}(x-a)(b-x) f^{\prime \prime}(x) d x .
$$

On the other hand, by the simple identity:

$$
\begin{aligned}
& \frac{1}{b-a} \int_{a}^{b} h(x) g(x) d x-\frac{1}{b-a} \int_{a}^{b} h(x) d x \cdot \frac{1}{b-a} \int_{a}^{b} g(x) d x \\
= & \frac{1}{b-a} \int_{a}^{b} h(x)\left[g(x)-\frac{1}{b-a} \int_{a}^{b} g(y) d y\right] d x,
\end{aligned}
$$

we may state that

$$
\begin{aligned}
& \int_{a}^{b}(x-a)(b-x) f^{\prime \prime}(x) d x-\int_{a}^{b}(x-a)(b-x) d x \cdot \frac{1}{b-a} \int_{a}^{b} f^{\prime \prime}(x) d x \\
= & \int_{a}^{b}(x-a)(b-x)\left[f^{\prime \prime}(x)-\left[f^{\prime} ; a, b\right]\right] d x,
\end{aligned}
$$

which is clearly equivalent to:

$$
\begin{aligned}
& \int_{a}^{b}(x-a)(b-x) f^{\prime \prime}(x) d x \\
= & \frac{(b-a)^{2}}{6}\left[f^{\prime}(b)-f^{\prime}(a)\right]+\int_{a}^{b}(x-a)(b-x)\left[f^{\prime \prime}(x)-\left[f^{\prime} ; a, b\right]\right] d x .
\end{aligned}
$$

Combining (2.2) with (2.4), we deduce (2.1).

Using the above representation, we may state the following result on the error of the perturbed trapezoid formula:

Theorem 4. With the assumptions of Lemma 1, we have

$$
\begin{aligned}
&\left|\int_{a}^{b} f(x) d x-\frac{b-a}{2}[f(a)+f(b)]+\frac{(b-a)^{3}}{12}\left[f^{\prime} ; a, b\right]\right| \\
& \leq\left\{\begin{array}{lr}
\frac{(b-a)^{3}}{12}\left\|f^{\prime \prime}-\left[f^{\prime} ; a, b\right]\right\|_{\infty} & \text { if } f^{\prime \prime} \in L_{\infty}[a, b] ; \\
\frac{1}{2}[B(q+1, q+1)]^{\frac{1}{q}}(b-a)^{2+\frac{1}{q}}\left\|f^{\prime \prime}-\left[f^{\prime} ; a, b\right]\right\|_{p}, & \text { if } f^{\prime \prime} \in L_{p}[a, b], \\
\frac{1}{8}(b-a)^{2}\left\|f^{\prime \prime}-\left[f^{\prime} ; a, b\right]\right\|_{1} & \text { if } f^{\prime \prime} \in L_{1}[a, b]
\end{array}\right.
\end{aligned}
$$


where $B$ is the Beta function and

$$
\begin{aligned}
\|g\|_{\infty} & :=e s s \sup |g(x)| \\
\|g\|_{p} & :=\left(\int_{a}^{b}|g(x)|^{s} d x\right)^{\frac{1}{s}}, s \geq 1 .
\end{aligned}
$$

Proof. Using Lemma 1, we have

$$
\begin{aligned}
& \left|\int_{a}^{b} f(x) d x-\frac{b-a}{2}[f(a)+f(b)]+\frac{(b-a)^{3}}{12}\left[f^{\prime} ; a, b\right]\right| \\
\leq & \frac{1}{2} \int_{a}^{b}(x-a)(b-x)\left|f^{\prime \prime}(x)-\left[f^{\prime} ; a, b\right]\right| d x=: M .
\end{aligned}
$$

It is obvious that

$$
\begin{aligned}
M & \leq \frac{1}{2}\left\|f^{\prime \prime}-\left[f^{\prime} ; a, b\right]\right\|_{\infty} \cdot \int_{a}^{b}(x-a)(b-x) d x \\
& =\frac{(b-a)^{3}}{12}\left\|f^{\prime \prime}-\left[f^{\prime} ; a, b\right]\right\|_{\infty}
\end{aligned}
$$

and the first part of (2.5) is proved.

Using Hölder's integral inequality, we have for $p>1, \frac{1}{p}+\frac{1}{q}=1$, that

$$
M \leq \frac{1}{2}\left(\int_{a}^{b}(x-a)^{q}(b-x)^{q} d x\right)^{\frac{1}{q}}\left(\int_{a}^{b}\left|f^{\prime \prime}(x)-\left[f^{\prime} ; a, b\right]\right|^{p} d x\right)^{\frac{1}{p}} .
$$

Now, using the transformation $x=(1-t) a+t b, t \in[0,1]$, we get

$$
\begin{aligned}
(x-a)^{q}(b-x)^{q} & =(b-a)^{2 q} t^{q}(1-t)^{q}, \\
d x & =(b-a) d t
\end{aligned}
$$

and thus

$$
\begin{aligned}
\int_{a}^{b}(x-a)^{q}(b-x)^{q} d x & =(b-a)^{2 q+1} \int_{0}^{1} t^{q}(1-t)^{q} d t \\
& =(b-a)^{2 q+1} B(q+1, q+1) .
\end{aligned}
$$

Using (2.7) we deduce the second part of (2.5).

Finally, as

$$
\begin{aligned}
M & \leq \frac{1}{2} \sup _{x \in[a, b]}\{(x-a)(b-x)\} \int_{a}^{b}\left|f^{\prime \prime}(x)-\left[f^{\prime} ; a, b\right]\right| d x \\
& =\frac{(b-a)^{2}}{8}\left\|f^{\prime \prime}-\left[f^{\prime} ; a, b\right]\right\|_{1}
\end{aligned}
$$


the theorem is completely proved.

The following corollary concerning the Euclidean norm is useful in practice.

Corrollary 1. If $f:[a, b] \rightarrow \mathbb{R}$ is such that $f^{\prime \prime} \in L_{2}[a, b]$, then we have the inequality:

$$
\begin{aligned}
& \left|\int_{a}^{b} f(x) d x-\frac{b-a}{2}[f(a)+f(b)]+\frac{(b-a)^{3}}{12}\left[f^{\prime} ; a, b\right]\right| \\
\leq & \frac{(b-a)^{3}}{2 \sqrt{30}}\left[\frac{1}{b-a}\left\|f^{\prime \prime}\right\|_{2}^{2}-\left[f^{\prime} ; a, b\right]^{2}\right]^{\frac{1}{2}} .
\end{aligned}
$$

Proof. Choosing in (2.5) $p=q=2$, we get

$$
\begin{aligned}
& \left|\int_{a}^{b} f(x) d x-\frac{b-a}{2}[f(a)+f(b)]+\frac{(b-a)^{3}}{12}\left[f^{\prime} ; a, b\right]\right| \\
\leq & \frac{1}{2}[B(3,3)]^{\frac{1}{2}}(b-a)^{2+\frac{1}{2}}\left\|f^{\prime \prime}-\left[f^{\prime} ; a, b\right]\right\|_{2} .
\end{aligned}
$$

However,

$$
B(3,3)=\frac{1}{30}
$$

and

$$
\begin{aligned}
\left\|f^{\prime \prime}-\left[f^{\prime} ; a, b\right]\right\|_{2} & =\left[\int_{a}^{b}\left(f^{\prime \prime}(x)-\left[f^{\prime} ; a, b\right]\right)^{2} d x\right]^{\frac{1}{2}} \\
& =\left[\int_{a}^{b}\left(f^{\prime \prime}(x)\right)^{2} d x-2 \int_{a}^{b} f^{\prime \prime}(x)\left[f^{\prime} ; a, b\right] d x+(b-a)\left[f^{\prime} ; a, b\right]^{2}\right]^{\frac{1}{2}} \\
& =\left(\left\|f^{\prime \prime}\right\|_{2}^{2}-2(b-a)\left[f^{\prime} ; a, b\right]^{2}+(b-a)\left[f^{\prime} ; a, b\right]^{2}\right)^{\frac{1}{2}} \\
& =\sqrt{b-a}\left(\frac{1}{b-a}\left\|f^{\prime \prime}\right\|_{2}^{2}-\left[f^{\prime} ; a, b\right]^{2}\right)^{\frac{1}{2}}
\end{aligned}
$$

then, by (2.9) we get $(2.8)$.

\section{Remark 2.}

1. The Grüss integral inequality for a function $g:[a, b] \rightarrow \mathbb{R}$ with $-\infty<m \leq g(x) \leq$ $M<\infty$ for almost every $x \in[a, b]$ states that (see for example [4, p. 296])

$$
0 \leq \frac{1}{b-a}\|g\|_{2}^{2}-\left(\frac{1}{b-a} \int_{a}^{b} g(x) d x\right)^{2} \leq \frac{1}{4}(M-m)^{2} .
$$


Applying (2.10) for the mapping $f^{\prime \prime}$ under the assumption that $\gamma \leq f^{\prime \prime}(x) \leq \Gamma$ for a.e. $x \in[a, b]$, we deduce

$$
\left(\frac{1}{b-a}\left\|f^{\prime \prime}\right\|_{2}^{2}-\left[f^{\prime} ; a, b\right]^{2}\right)^{\frac{1}{2}} \leq \frac{1}{2}(\Gamma-\gamma)
$$

and then, by (2.8) we deduce

$$
\left|\int_{a}^{b} f(x) d x-\frac{b-a}{2}[f(a)+f(b)]+\frac{(b-a)^{3}}{12}\left[f^{\prime} ; a, b\right]\right| \leq \frac{(b-a)^{3}}{4 \sqrt{30}}(\Gamma-\gamma) .
$$

which is not as good as the result in (1.3).

2. Chebychev's inequality for a differentiable function $g:[a, b] \rightarrow \mathbb{R}$, with $g^{\prime} \in L_{\infty}[a, b]$ states that (see [4, p. 297])

$$
0 \leq \frac{1}{b-a}\|g\|_{2}^{2}-\left(\frac{1}{b-a} \int_{a}^{b} g(x) d x\right)^{2} \leq \frac{1}{12}(b-a)^{2}\left\|g^{\prime}\right\|_{\infty}^{2} .
$$

Applying (2.12) for the mapping $f^{\prime \prime}$ under the assumption that $f^{\prime \prime \prime} \in L_{\infty}[a, b]$, we deduce by (2.8) that

$$
\left|\int_{a}^{b} f(x) d x-\frac{b-a}{2}[f(a)+f(b)]+\frac{(b-a)^{3}}{12}\left[f^{\prime} ; a, b\right]\right| \leq \frac{(b-a)^{4}\left\|f^{\prime \prime \prime}\right\|_{\infty}}{12 \sqrt{10}} .
$$

3. Lupass's inequality for a differentiable function $f$ with $f^{\prime \prime \prime} \in L_{2}[a, b]$ states that (see $[4$, p. 301])

$$
0 \leq \frac{1}{b-a}\|g\|_{2}^{2}-\left(\frac{1}{b-a} \int_{a}^{b} g(x) d x\right)^{2} \leq \frac{b-a}{\pi^{2}}\left\|g^{\prime}\right\|_{2}^{2} .
$$

Applying (2.14) for the mapping $f^{\prime \prime}$ under the assumption that $f^{\prime \prime \prime} \in L_{2}[a, b]$, we deduce, by (2.8), that

$$
\left|\int_{a}^{b} f(x) d x-\frac{b-a}{2}[f(a)+f(b)]+\frac{(b-a)^{3}}{12}\left[f^{\prime} ; a, b\right]\right| \leq \frac{(b-a)^{\frac{7}{2}}\left\|f^{\prime \prime \prime}\right\|_{2}}{2 \pi \sqrt{30}} .
$$

The following lemma of representation also holds.

Lemma 2. Let $f:[a, b] \rightarrow \mathbb{R}$ be a differentiable function such that $f^{\prime}$ is absolutely continuous on $[a, b]$. We have the representation:

$$
\begin{aligned}
& \int_{a}^{b} f(x) d x-\frac{b-a}{2}[f(a)+f(b)]+\frac{(b-a)^{3}}{12}\left[f^{\prime} ; a, b\right] \\
= & \frac{1}{2} \int_{a}^{b}\left(x-\frac{a+b}{2}\right)^{2}\left[f^{\prime \prime}(x)-\left[f^{\prime} ; a, b\right]\right] d x,
\end{aligned}
$$


where $\left[f^{\prime} ; a, b\right]$ is the divided difference.

Proof. The identity (2.16) may be proven directly.

A simpler proof uses Lemma 1 as follows.

Since

$$
(x-a)(b-x)=\left(\frac{a-b}{2}\right)^{2}-\left(x-\frac{a+b}{2}\right)^{2}
$$

and

$$
\begin{aligned}
& \frac{1}{2} \int_{a}^{b}(x-a)(b-x)\left\{\left[f^{\prime} ; a, b\right]-f^{\prime \prime}(x)\right\} d x \\
= & \frac{1}{2} \int_{a}^{b}\left[\left(\frac{a-b}{2}\right)^{2}-\left(x-\frac{a+b}{2}\right)^{2}\right]\left\{\left[f^{\prime} ; a, b\right]-f^{\prime \prime}(x)\right\} d x \\
= & \frac{1}{2} \int_{a}^{b}\left(\frac{a-b}{2}\right)^{2}\left\{\left[f^{\prime} ; a, b\right]-f^{\prime \prime}(x)\right\} d x-\frac{1}{2} \int_{a}^{b}\left(x-\frac{a+b}{2}\right)^{2}\left\{\left[f^{\prime} ; a, b\right]-f^{\prime \prime}(x)\right\} d x \\
= & \frac{1}{2} \int_{a}^{b}\left(x-\frac{a+b}{2}\right)^{2}\left\{f^{\prime \prime}(x)-\left[f^{\prime} ; a, b\right]\right\} d x,
\end{aligned}
$$

then by (2.1) we deduce (2.16).

The following result also holds.

Theorem 5. With the assumptions of Lemma 2, we have the inequality

$$
\begin{aligned}
& \left|\int_{a}^{b} f(x) d x-\frac{b-a}{2}[f(a)+f(b)]+\frac{(b-a)^{3}}{12}\left[f^{\prime} ; a, b\right]\right| \\
& \leq\left\{\begin{array}{lc}
\frac{(b-a)^{3}}{24}\left\|f^{\prime \prime}-\left[f^{\prime} ; a, b\right]\right\|_{\infty} & \text { if } f^{\prime \prime} \in L_{\infty}[a, b] ; \\
\frac{(b-a)^{2+\frac{1}{q}}}{8(2 q+1)^{\frac{1}{q}}}\left\|f^{\prime \prime}-\left[f^{\prime} ; a, b\right]\right\|_{p}, & \text { if } f^{\prime \prime} \in L_{p}[a, b], \\
\frac{(b-a)^{2}}{8}\left\|f^{\prime \prime}-\left[f^{\prime} ; a, b\right]\right\|_{1} . & p>1, \frac{1}{p}+\frac{1}{q}=1 ;
\end{array}\right.
\end{aligned}
$$

Proof. Using Lemma 2, we have:

$$
\begin{aligned}
& \left|\int_{a}^{b} f(x) d x-\frac{b-a}{2}[f(a)+f(b)]+\frac{(b-a)^{3}}{12}\left[f^{\prime} ; a, b\right]\right| \\
\leq & \frac{1}{2} \int_{a}^{b}\left(x-\frac{a+b}{2}\right)^{2}\left|f^{\prime \prime}(x)-\left[f^{\prime} ; a, b\right]\right| d x=: N .
\end{aligned}
$$


It is obvious that

$$
\begin{aligned}
N & \leq \frac{1}{2}\left\|f^{\prime \prime}-\left[f^{\prime} ; a, b\right]\right\|_{\infty} \cdot \int_{a}^{b}\left(x-\frac{a+b}{2}\right)^{2} d x \\
& =\frac{(b-a)^{3}}{24}\left\|f^{\prime \prime}-\left[f^{\prime} ; a, b\right]\right\|_{\infty} .
\end{aligned}
$$

Using Hölder's integral inequality,we have for $p>1, \frac{1}{p}+\frac{1}{q}=1$, that

$$
N \leq \frac{1}{2}\left(\int_{a}^{b}\left|x-\frac{a+b}{2}\right|^{2 q} d x\right)^{\frac{1}{q}}\left(\int_{a}^{b}\left|f^{\prime \prime}(x)-\left[f^{\prime} ; a, b\right]\right|^{p} d x\right)^{\frac{1}{p}}
$$

However,

$$
\int_{a}^{b}\left|x-\frac{a+b}{2}\right|^{2 q} d x=2 \int_{\frac{a+b}{2}}^{b}\left(x-\frac{a+b}{2}\right)^{2 q} d x=\frac{(b-a)^{2 q+1}}{4^{q}(2 q+1)}
$$

and then, by (2.19), we deduce the second part of (2.17).

Finally, as

$$
\sup _{x \in[a, b]}\left|x-\frac{a+b}{2}\right|^{2}=\frac{(b-a)^{2}}{4},
$$

then

$$
N \leq \frac{(b-a)^{2}}{8}\left\|f^{\prime \prime}-\left[f^{\prime} ; a, b\right]\right\|_{1},
$$

proving the last part of (2.17).

Remark 3. It is obvious that the first inequality in (2.17) is better than the similar one in (2.5), while the last ones are indentical.

Remark 4. A computer simulation for the function $\frac{1}{2}[B(q+1, q+1)]^{\frac{1}{q}}, \frac{1}{8} \cdot \frac{1}{(2 q+1)^{\frac{1}{q}}}$ shows that the latter is smaller for any $q>1$, but we do not have an analytic proof of this fact. We conjecture that the second inequality in (2.7) is better than the second inequality in (2.5) for every $p>1, \frac{1}{p}+\frac{1}{q}=1$.

For $p=q=2$, we get the following partcular case for the euclidean norm:

Corolary 2. If $f:[a, b] \rightarrow \mathbb{R}$ is such that $f^{\prime \prime} \in L_{2}[a, b]$, then

$$
\begin{aligned}
& \left|\int_{a}^{b} f(x) d x-\frac{b-a}{2}[f(a)+f(b)]+\frac{(b-a)^{3}}{12}\left[f^{\prime} ; a, b\right]\right| \\
\leq & \frac{(b-a)^{3}}{8 \sqrt{5}}\left[\frac{1}{b-a}\left\|f^{\prime \prime}\right\|_{2}^{2}-\left[f^{\prime} ; a, b\right]^{2}\right]^{\frac{1}{2}} .
\end{aligned}
$$


Remark 5. We note that (2.20) is a better result that the corresponding one in (2.8), and thus, we may note the following better results following via Grüss type inequalities.

If $f^{\prime \prime}$ is such that $\gamma \leq f^{\prime \prime} \leq \Gamma$ for a.e. $x \in[a, b]$, then by Grüss' (2.10), we have

$$
\left|\int_{a}^{b} f(x) d x-\frac{b-a}{2}[f(a)+f(b)]+\frac{(b-a)^{3}}{12}\left[f^{\prime} ; a, b\right]\right| \leq \frac{(b-a)^{3}(\Gamma-\gamma)}{16 \sqrt{5}} .
$$

If $f^{\prime \prime \prime} \in L_{\infty}[a, b]$, then by the Chebychev inequality (2.12), we have

$$
\left|\int_{a}^{b} f(x) d x-\frac{b-a}{2}[f(a)+f(b)]+\frac{(b-a)^{3}}{12}\left[f^{\prime} ; a, b\right]\right| \leq \frac{(b-a)^{4}\left\|f^{\prime \prime \prime}\right\|_{\infty}}{16 \sqrt{15}} .
$$

Finally, if $f^{\prime \prime \prime} \in L_{2}[a, b]$, then by the Lupaş inequality (2.14), we have:

$$
\left|\int_{a}^{b} f(x) d x-\frac{b-a}{2}[f(a)+f(b)]+\frac{(b-a)^{3}}{12}\left[f^{\prime} ; a, b\right]\right| \leq \frac{(b-a)^{\frac{7}{2}}\left\|f^{\prime \prime \prime}\right\|_{2}}{8 \pi \sqrt{5}} .
$$

\section{Applications for Expectation}

Let $X$ be a random variable having the p.d.f., $f:[a, b] \rightarrow \mathbb{R}$ and the cumulative distribution function $F:[a, b] \rightarrow[0,1]$, i.e.,

$$
F(x)=\int_{a}^{x} f(t) d t, x \in[a, b] .
$$

The following result holds.

Theorem 6. With the above assumptions and if the p.d.f. is absolutely continuous on $[a, b]$, then we have the inequality:

$$
\begin{aligned}
& \left|E(X)-\frac{a+b}{2}-\frac{(b-a)^{2}}{12}[f(b)-f(a)]\right| \\
& \leq\left\{\begin{array}{lc}
\frac{(b-a)^{3}}{24}\left\|f^{\prime}-[f ; a, b]\right\|_{\infty} & \text { if } f^{\prime} \in L_{\infty}[a, b] \\
\frac{(b-a)^{2}+\frac{1}{q}}{8(2 q+1)^{\frac{1}{q}}}\left\|f^{\prime}-[f ; a, b]\right\|_{p} & \text { if } f^{\prime} \in L_{p}[a, b], \\
\frac{(b-a)^{2}}{8}\left\|f^{\prime}-[f ; a, b]\right\|_{1} . & p>1, \frac{1}{p}+\frac{1}{q}=1 ;
\end{array}\right.
\end{aligned}
$$

Proof. Applying Theorem 5 for the c.d.f., F, we may write that

$$
\left|\int_{a}^{b} F(t) d t-\frac{F(a)+F(b)}{2}(b-a)+\frac{(b-a)^{2}}{12}[f(b)-f(a)]\right|
$$




$$
\leq\left\{\begin{array}{c}
\frac{(b-a)^{3}}{24}\left\|f^{\prime}-[f ; a, b]\right\|_{\infty} \\
\frac{(b-a)^{2+\frac{1}{q}}}{8(2 q+1)^{\frac{1}{q}}}\left\|f^{\prime}-[f ; a, b]\right\|_{p} \\
\frac{(b-a)^{2}}{8}\left\|f^{\prime}-[f ; a, b]\right\|_{1} .
\end{array}\right.
$$

However, $F(a)=0, F(b)=1$ and

$$
\int_{a}^{b} F(t) d t=b-E(X)
$$

and then, by (3.2) we deduce the desired inequality (3.1).

\section{References}

[1] K. E. Atkinson, An Introduction to Numerical Analysis, Second Edition, Wiley and Sons, 1989.

[2] P. Cerone and S. S. Dragomir, Trapezoidal type rules from an inequalities point of view, Handbook of Analytic-Computational Methods in Applied Mathematics, G. A. Anastassiou (Ed), CRC Press, New York (2000), 65-134.

[3] S. S. Dragomir, P. Cerone and A. Sofo, Some remarks on the trapezoid rule in numerical integration, Indian J. of Pure and Appl. Math. 31 (2000), 475-494. Preprint: RGMIA Res. Rep. Coll. 2 (1999), Article 1. [ONLINE] http://rgmia.vu.edu.au/v2n5.html

[4] D. S. Mitrinović, J. E. Pečarić and A. M. Fink, Classical and New Inequalities in Analysis, Kluwer Academic Publishers, 1993.

School of Communications and Informatics, Victoria University of Technology, PO Box 14428, Melbourne City MC, Victoria 8001, Australia.

E-mail: neil@sci.vu.edu.au

URL: http://sci.vu.edu.au/staff/neilb.html

E-mail: sever@matilda.vu.edu.au

URL: http://rgmia.vu.edu.au/SSDragomirWeb.html 